\title{
Effect of Island Size on the Packing Density in the Early Stages of Alkylsilane-Based Monolayer Self Assembly
}

\author{
Bo H. Lee and Myung M. Sung \\ Department of Chemistry, Kookmin Lniversity, Seoul 136-702, Korea. "E-mail: smmakookmin.ackr \\ Received September $1+1,2004$
}

\begin{abstract}
The early stage of the self assembly for octadecyltrichlorosilane (OTS)-based monolayers is investigated using atomic force microscopy (AFM). Height measurements using AFM prove that the island height of the monolayers gradually increases with increasing the island size. and is close to the limiting value ( $\mathrm{h}=\sim 25 \AA$ ) after $\mathrm{d}=-600 \mathrm{~nm}$ in size. Since the theoretical length of a covalently bound OTS molecule is $26.2 \AA$. the limiting value of the island height means that the islands with $\mathrm{d} \geq 600 \mathrm{~mm}$ consist of close-packed. fully extended chains. The heights for the islands with $\mathrm{d}<600 \mathrm{~mm}$ are lower than the limiting value and decrease with decreasing the island sizes. This observation indicates that the OTS molecules in the small islands are less densely packed. and that the packing densities of the islands increase as the islands grow in size.
\end{abstract}

Key Words : Self-assembled monolayers. Growth mechanism

\section{Introduction}

Self-assembled monolaỵers (SAMs) are thin organic films which form spontaneously on solid surfaces. Several different varieties of SAMs have been investigated including alkanethiols $\left(\mathrm{CH}_{3}\left(\mathrm{CH}_{2}\right)_{r+1} \mathrm{SH}\right)$ on $\mathrm{Au}, \mathrm{Ag}$. and $\mathrm{Cu}$. and alkr'trichlorosilanes $\left(\mathrm{CH}_{3}\left(\mathrm{CH}_{2}\right)_{n-1} \mathrm{SiCl}_{3}\right)$ on $\mathrm{SiO}_{2}, \mathrm{Al}_{2} \mathrm{O}_{3}$. and mica. ${ }^{1-4}$ A class of widely used self-assembled monolayers (SAMs) is based on alkyltricllorosilane precursor molecules. which through hydrolysis and polymerization. produce alkylsiloxane SAMs on many hydrophilic substrates. In the case of octadecyltrichlorosilane (OTS)-based SAMs on $\mathrm{SiO}_{3}$, adsorption takes place through the hydrol$y$ sis of the $\mathrm{Si}-\mathrm{Cl}$ bonds to form $\mathrm{Si}-\mathrm{OH}$ groups. All $\mathrm{Si}-\mathrm{Cl}$ bonds become hydrolyzed as no chlorine is detected following monolayer formation. "The $\mathrm{OH}$ groups undergo condensation reactions to form $\mathrm{Si}-\mathrm{O}-\mathrm{Si}$ cross linking bonds between adjacent head groups. It is believed that these also interact with $\mathrm{OH}$ groups on the oxidized surface. forming Si-O-Si bonds to the substrate. Water was found to play a key role in the formation step. ${ }^{5-7}$ It has been proposed that a thin water film exists on the hydrophilic $\mathrm{SiO}_{2}$ surface and that the OTS molecules physisorb on this water film. ${ }^{6.7} \mathrm{In}$ this stage. the OTS molecules exists in a highly mobile state akin to the equilibrium state of Langmuir films. allowing them to pack more closely before condensation reaction takes place. at which point they become pinned to the surface. ${ }^{8 . \overline{4}}$

The existence of a threshold temperature for high quality silanization was discovered by Brozoska et al. who suggested that this temperature is analogous to the triple point of a Langmuir film. ${ }^{10-12}$ Later. it was found that silanization occurs via three markedly different growth regimes. separated by well-defined transition temperatures. ${ }^{8}$ For $\mathrm{T}<16^{\circ} \mathrm{C}$. the OTS-based monolayer forms by island growth only, the substrate between islands remaining essentially unfilled: such a growth pattern is expected if a Langmuir film nucleates liquid-condensed (LC) domains coexisting with the gas phase below the triple point. Thus, the triple point is about $16^{\circ} \mathrm{C}$ for the OTS-based monolayer. For $\mathrm{T}>16^{\circ} \mathrm{C}$. island growth is observed to occur more slowly, while the substrate between islands is gradually filled in with OTS molecules. This growth regime is attributed to nucleation of LC domains coexisting with a liquid-expanded (LE) phase. This growth mechanism operates only up to a characteristic temperature (about $40^{\circ} \mathrm{C}$ for OTS). above which no island growth is observed but homogeneous growth instead dominates

The early stage of the self assembly for the OTS-based monolayers has been the subject of debate. For the OTSbased monolayers on mica and oxidized silicon. closepacked islands were found to nucleate and grow directly from the gas phase below the triple point ${ }^{8.9 .13-18}$ At the early stage. large branched islands with a diameter around 1 tam were surrounded by smaller circular islands. The height of the islands did not depend on the island size, i.e. small islands with a diameter around $100 \mathrm{~nm}$ already exhibited the length of a fully extended OTS chain. ${ }^{13.17}$ The smaller islands were assigned to preorganized polysiloxane assemblies that were built in solution prior adsorption and the larger islands to aggregates of these assemblies. ${ }^{13}$ Recently: however. the small circular islands have been reported to exhibit a randon height distribution. whereas the large branched islands show a fairly constant height $(\sim 25 \mathrm{~A}) .^{18}$

In this article. the early stage of the self assembly for the OTS-based monolayers is investigated by monitoring the monolayer heights using atomic force microscopy (AFM). Height measurements by AFM prove that the height of the OTS islands gradually increases with increasing the island size, and is close to the limiting value $(\sim 25 \mathrm{~A})$ after about $600 \mathrm{~mm}$ in size. This observation indicates that. in the early stage of the self assembly. the OTS molecules in the small islands are less densely packed and the packing densities of the islands increase as the island size increases. 


\section{Experimental Section}

Materials. Octadecyltrichlorosilane $\left[\mathrm{CH}_{3}\left(\mathrm{CH}_{2}\right)_{17} \mathrm{SiCl}_{3}\right]$ (Aldrich: 97\%), hexane (Aldrich; anhydrous, 99\%), hexadecane (Aldrich; anhydrous, 99\%), chloroform (Aldrich; anhydrous, 99\%), and carbon tetrachloride (Aldrich; anhydrous, $99.5 \%$ ) were used as received. Deionized water was purified with a Millipore Milli $Q$ plus system, distilled over $\mathrm{KMnO}_{4}$, and then passed through the Millipore Simplicity system.

Preparation of Si Substrates. The Si substrates used for SAMs formation in this research were cut from n-type (100) wafers with resistivity in the range $1-5 \Omega \mathrm{cm}$. The Si substrates were initially treated by a chemical cleaning process, which involves degreasing. $\mathrm{HNO}_{3}$ boiling. $\mathrm{NH}_{4} \mathrm{OH}$ boiling (alkali treatment), $\mathrm{HCl}$ boiling (acid treatment). rinsing in deionized water and blow-drying with nitrogen. proposed by Ishizaka and Shiraki ${ }^{10}$ to remove contaminants. Oxidized silicon (100) samples were prepared by chemical oxidation with peroxy-sulfuric acid, followed by etching in concentrated hydrogen fluoride, and finally by reoxidation in a peroxy-sulfuric acid solution. This treatment results in a clean, oxidized surface possessing the same topography as the original wafer $(2.2=0.4 \AA \mathrm{rms})$.

Preparation of Octadecylsiloxane SAMs Octadecyltrichlorosilane (OTS) solutions were prepared in various concentrations $(0.1-10 \mathrm{mM})$ in a solvent mixture of $4: 1$ volume hexadecane/chloroform. The oxidized samples were then introduced into the O'S solutions, where they were kept for specified amounts of time. SAMs growth was quenched by rinsing the sample in carbon tetrachloride. The OTS solutions were made in a glovebox purged with argon immediately before use, and alkylsiloxane SAMs were formed in air under controlled relative humidity and temperature. Our experiments were carried out in an environmental chamber, where we can simultaneously control relative humidity $( \pm 2 \%)$ and temperature $\left( \pm 1{ }^{\circ} \mathrm{C}\right)$. Relative humidity and temperature were kept fixed in all experiments at $50 \%$ and $10^{\circ} \mathrm{C}$.

Analysis Techniques. Immediately after the samples prepared, all atomic force microscopy (AFM) measurements were carried out with a XE-100 SPM (PSIA, Korea) operated in tapping mode (IM) and contact mode (CM). Japping Si-Cantilevers (XE-CAI-NCSI, PSIA, Korea) with resonance frequencies in the order of $300-400 \mathrm{kHz}$ and spring constants between 20 and $40 \mathrm{~N} / \mathrm{m}$ have been used for the experiments. Contact cantilevers (CSC12, PSIA. Korea) in constant contact with the surface scanned across the substrate at a constant rate $(5 \mu \mathrm{m} / \mathrm{s})$ with a constant force $(0.5 \mathrm{nN})$.

\section{Results and Discussion}

We first investigated SAM growth from the O'S solution of low concentration $(0.1 \mathrm{mM})$ for various amounts of time. At $10^{\circ} \mathrm{C}$, the $\mathrm{O} / \mathrm{S}$-based monolayer forms by pure island growth, and essentially no O'S molecules are found on the substrate between islands. At this low concentration, the growth rate of the SAMs is so reduced that the early stage of the SAM formation can be investigated in detail by AFM. The height measurement by [M-AFM is quite complicated and strongly varies depending on the experimental parameters (e.g., oscillation amplitude and the damping ratio), moisture on the surface, and cantilever tip quality. ${ }^{20}$ On the other hand, the height measurement by $\mathrm{CM}-\mathrm{AFM}$ is much more reliable than that by $\mathrm{TM}-\mathrm{AFM}$. The $\mathrm{CM}-\mathrm{AFM}$, however, has the risk of damaging the sample due to high loading forces or lateral shear forces. In this experiment, therefore the heights of all the samples were measured by both TM-AFM and CM-AFM in order to conform the reliability of IMAFM data. All IM-AFM data shown in this article were coincident with corresponding CM-AFM data.

Figure I shows typical TM-AFM images of six Si samples immersed in the O'TS solution for $1 \mathrm{~s}, 3 \mathrm{~s}, 7 \mathrm{~s}, 12 \mathrm{~s}, 30 \mathrm{~s}$, and 100 s. Immediately after placing the $\mathrm{Si}$ substrate in the solution, OIS islands nucleate on the surface and begin to grow. For a 1 -s sample [Figure 1 (a)], the monolayer consists of sinall circular dots of uniform size $(\mathrm{d}=42 \pm 2 \mathrm{~nm})$ with a mean island height of $\mathrm{h}=5 \pm 2 \AA$. The 3 -s sample [Figure 1 (b)] shows that the circular islands grow in size and height (d $=60 \pm 3 \mathrm{~nm}, \mathrm{~h}=6 \pm 3 \AA$ ). On the 7-s sample [Figure l(c)] these islands continue to grow in size and height $(\mathrm{d}=90=$ $10 \mathrm{~nm}, \mathrm{~h}=\mathrm{ll} \pm 5 \AA$ ), and the number of the islands increases. The mean island size and height for the 12-s sample [Figure $\mathrm{I}(\mathrm{d})]$ increase to $\mathrm{d}=140 \pm 23 \mathrm{~nm}$ and $\mathrm{h}=16$ $\pm 7 \AA$. It should be noted that the island size and height distributions become much broader, indicating that several OTS islands with different sizes and heights are formed. After a 30 -s immersion time [Figure $1(\mathrm{e})$ ], these islands

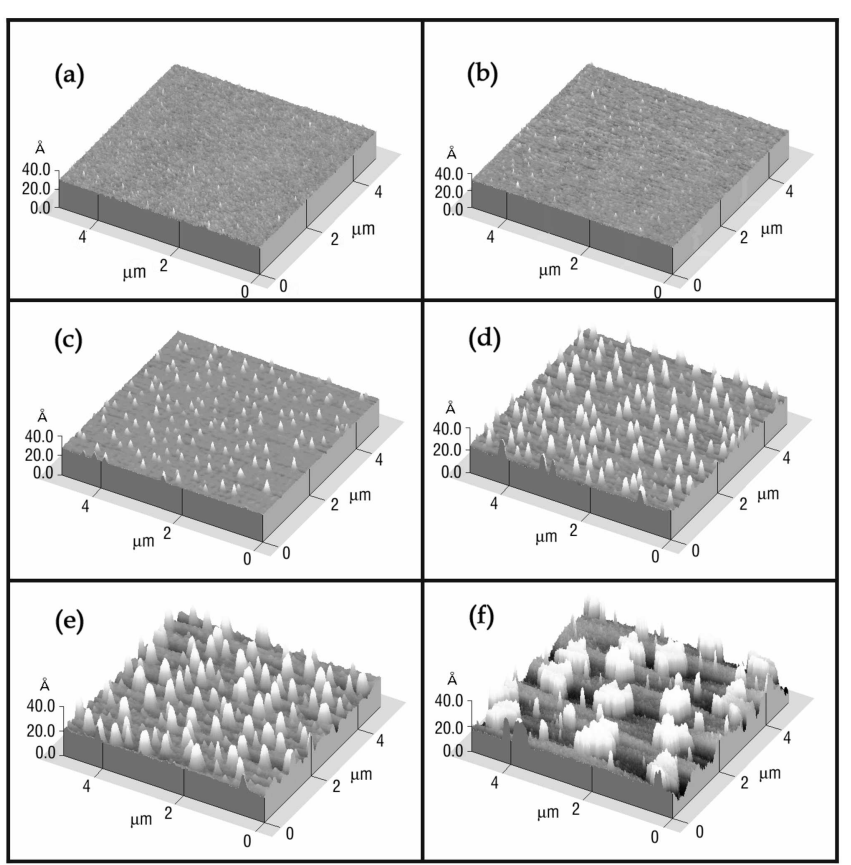

Figure I. IM- $\wedge \mathrm{F}$ images of the time-resolved sequence of partial SAMs growth al $10^{\circ} \mathrm{C}$. (a) I s. (b) $3 \mathrm{~s}$, (c) $7 \mathrm{~s}$, (d) $12 \mathrm{~s}$, (c) 30 s. (f) $100 \mathrm{~s}$ 

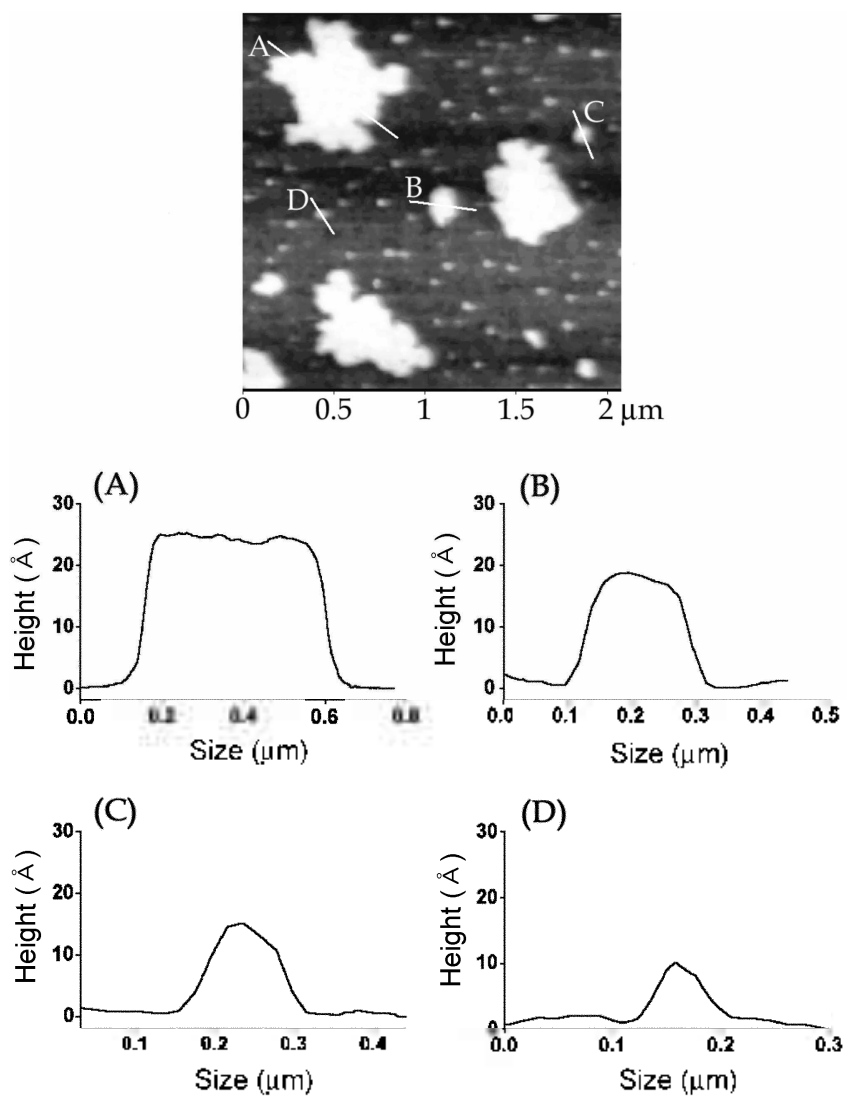

Figure 2. TM-AFM image and cross sections of a partial SAMs grown at $10^{\circ} \mathrm{C} \cdot 10{ }^{\circ} 100 \mathrm{~s}$.

continue to grow in size and height $(\mathrm{d}=200=100 \mathrm{~nm}, \mathrm{~h}=$ $19=11 \AA$ ) and the distributions become broader. The $100-\mathrm{s}$ sample [figure 1(f)] shows large branched islands with smaller circular islands. The large branched islands have $\mathrm{d}=$ $750=50 \mathrm{~nm}$ and $\mathrm{h}=25 \pm 2 \AA$. The smaller circular islands with the broad size and height distribution $(d=160=90 \mathrm{~nm}$, $\mathrm{h}=17 \pm 9 \AA$ ) are visible between the larger branched islands.

Figure 2 shows IM-AFM image and cross sections of the monolayer grown from the OIS solution of low concentration $(0.1 \mathrm{mM})$ for $100 \mathrm{~s}$. The large branched islands have the height, $\mathrm{h}=25 \pm 2 \AA$ [Figure 2(A)], compatible with the length of a fully extended OTS chain. The smaller circular islands with several different sizes and heights are visible between the larger branched islands. The cross sections of the smaller islands show that the island height decreases with decreasing island size. For the island with size $d=202$ $\mathrm{nm}$, the height is $19 \AA$ [rigure 2(B)]. The island with $\mathrm{d}=130$ $\mathrm{nm}$ is reduced in height to $15 \AA$, as shown in rigure $2(\mathrm{C})$. The small island with $d=80 \mathrm{~nm}$ continues to decrease in height to $10 \AA$ [rigure 2(D)]. This behavior suggests that the height of the OIS-based SAMs obviously depends on the island size in the early stage of the self-assembly.

Quantitative information about the height dependence on the island size was obtained from AFM measurements of 400 different SAMs-coated samples prepared from OIS solutions of various concentrations $(0.1-10 \mathrm{mM})$ and for

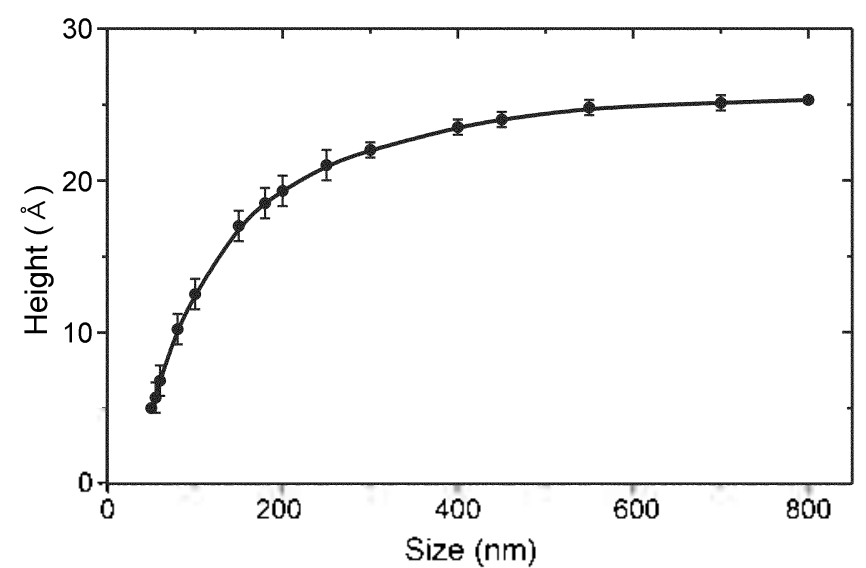

Figure 3. Island height as a function of island size for the 400 diferent SAMs-coaled samples prepared trom the OTS solutions of various concentrations $(0.1-10 \mathrm{mM})$ and for various amounts of SAMs gron th time (I-100 s).

various growth times ( $\mathrm{l}-200 \mathrm{~s}$ ). The height of the $\mathrm{O}$ IS-based SAMs on the oxidized $\mathrm{Si}$ was plotted as a function of the island size. Figure 3 shows that the island height of the monolayers increases with increasing island size, and is close to the limiting value $(h=-25 \AA)$ after $d=-600 \mathrm{~nm}$ in size. Since the theoretical length of a covalently bound OTS molecule is $26.2 \AA$, this limiting value of the island height means that the islands with $d>600 \mathrm{~nm}$ consist of closepacked, fully extended chains. The heights for the islands with $d<600 \mathrm{~nm}$ are lower than the limiting value and fall off as the island sizes are reduced. This observation indicates that the OIS molecules in the small islands are less densely packed and that the packing densities of the islands decrease as the island sizes decrease.

In summary, our investigations of self assembly for the OTS-based monolayers reveal that the island height of the monolayers obviously depends on the island size, up to $d=$ $600 \mathrm{~nm}$. The islands with $d>600 \mathrm{~nm}$ consist of closepacked, fully extended chains. This observation indicates that the packing densities of the OIS islands depend on the island size in the early stage of the self assembly.

Acknowledgment. This work was supported by a program of National Research Laboratory from the Ministry of Science and Jechnology, and a National R\&D Project for Nano Science and Technology from the Ministry of Science and Technology.

\section{References}

1. UIman. A. An Introduction to L Iftethin Organic Films: Academic Press: Boston. MA. 1991.

2. Swalcn. J. D.: Allara. D. L.: Andrade. J. D.: Chandross. E. A.: (iaroff, S.: Isracklachvili, J.: MeCarthy, T. J.: Murray. R.: Pease. R. l.: Rabolt. J. J.: Wyme. K. J.: Yu. II. Langmuir 1987. 3.932.

3. Sung. M. M.: Yun. W. J.: Lee. S. S.: Kim. Y. Bult Koreth them. 5oc. 2003. 24. 610 .

4. Sung. M. M.: Kim. Y. Bull. Kotean Chem. Soc 2001. 2.2 748.

5. Wasserman. S. R.: Tao. Y.-T.: Whitesides. G. M. Langmur 1989. 
5.1074 .

6. Silberzan. P.: Leger. L.: Ausserre. D.: Benattar. J. J. Langmit 1991. 7. 1647.

7. Allara, D. L.: Parikh, A. N.: Rondelez, F. Langmiri 1995. 11. 2357.

8. Carraro. C.: Yauw O. W.: Sung, M. M: Maboudian. R J. Phns. Chem. B 1998.102.4441

9. Sung. M. M.: Carraro. C.: Yauw: O. W.: Kim. Y:: Maboudian. R. J. Ph s Chem. B 2000. 104. 1556.

10. Brozoska, I. B.: Shahidzadeh, N.: Rondelez, F. Natme 1992, 360. 719

11. Brozoska. J. B.: Ben Azouz, I.: Rondelez, F. Langmir 1994. 10. 4367

12. Parikh. A. N.: Allara. D. L.: Azouz. I. B.: Rondelez. F. J. Phns. Chem. 1994. 98. 7577.
13. Schwartz. D. K.: Steinberg. S.: Israelachvili. T: Zasadzinski. T. A. N. Phos Rev: Lett. 1992. 69. 3354

14. Bierbaum. K.: Grunze. A. A.: Baski. A. A.: Chi. L. F.: Schrepp. W. Fuchs. H. Langmir 1995, 11.2143.

15. Vallant, T.: Brumner, B.: Mayer. U.; Hotfmann, H: Leitner. T.: Resch. R: Friedbacher. G J. Plys. Chem. B 1998. 102 7190 .

16. Britt. D. W.: Hady. V. J. Colloid Interf. Sci. 1996. 178. 775.

17. Balgar. T.: Bautista. R.: Hartmann1. N.: Hasselbritn. E. Surface Science 2003. 532-535, 963 .

18. Rozlosnik, N.: Gerstenberg, M. C.: Larsen, N. B. Langmuir 2003. 19. 1182 .

19. Ishizaki. A.: Shiraki. Y. J. Electrochem. Soc. 1986. 133.666.

20. Bast1ar. B.: Friedbacher. G.: Brun1er. H.: Vallant. T.: Mayer. U.: Hotẗmann. H. Applied Surface Science 2001. 171. 213. 